\title{
Cerebriform nevus sebaceous: A rare clinical variant of nevus sebaceous
}

\author{
Funda Tamer', Mehmet Eren Yuksel ${ }^{2}$
}

${ }^{1}$ Department of Dermatology, Ufuk University School of Medicine, Ankara, Turkey, ${ }^{2}$ Department of General Surgery, Aksaray University School of Medicine, Aksaray, Turkey

Corresponding author: Dr. Funda Tamer, E-mail: fundatmr@yahoo.com

Sir,

A 30-year-old Caucasian female presented with a hairless plaque on her head. The patient admitted that she had this asymptomatic lesion since birth. However, the patient complained that the size of the lesion had gradually increased in the last ten years. The physical examination of the patient revealed a firm, well defined, pink-orange coloured, oval, alopecic plaque with cerebriform surface measuring $3 \times 2 \mathrm{~cm}$ on the vertex (Fig. 1). The past medical history was unremarkable. Moreover, there was no history of trauma, skeletal, neurological or ocular abnormalities. In the light of clinical findings and the history of the patient, the lesion was diagnosed as cerebriform nevus sebaceous. Because of the risk of malignant transformation, surgical excision of the lesion was advised. However, the patient refused surgical intervention. Therefore, regular follow up was recommended.

Nevus sebaceous is a rare cutaneous hamartoma which consists of sebaceous glands [1]. It is usually present at birth as a yellowish-orange coloured, alopecic plaque with a smooth surface on the scalp. However, the lesion may thicken and become verrucous or nodular during adolescence [2]. Although nevus sebaceous is a benign lesion, it may give rise to basal cell carcinoma, sebaceous carcinoma, apocrine carcinoma and malignant eccrine poroma. Moreover, large sebaceous nevi may be associated with neurocutaneous syndrome which is associated with neurological defects and skeletal abnormalities [1].

Cerebriform nevus sebaceous is a very rare clinical variant of nevus sebaceous [3]. It was first described by Ramesh et al. in 1988 [4]. Since then, only 13 cases of cerebriform nevus sebaceous have been reported in English medical literature to the best of our knowledge [1]. Hereby, we would like to share the clinical appearance of cerebriform nevus sebaceous with our colleagues (Fig. 1)

Cerebriform nevus sebaceous is characterized by large, verrucous, pink, alopecic nodules with cerebriform surface $[1,4]$. The diagnosis is usually made by its clinical features, however histopathological examination is mandatory in order to reach a definitive diagnosis. It has been suggested that PTCH gene deletion and mosaic mutations in HRAS and KHAS genes might play role in development of nevus sebaceous. Nevertheless, the cause of cerebriform appearance of the lesion remains unknown [4]. Seborrheic keratosis, epidermal nevus and warts should be included in the differential diagnosis of cerebriform nevus sebaceous. Surgical

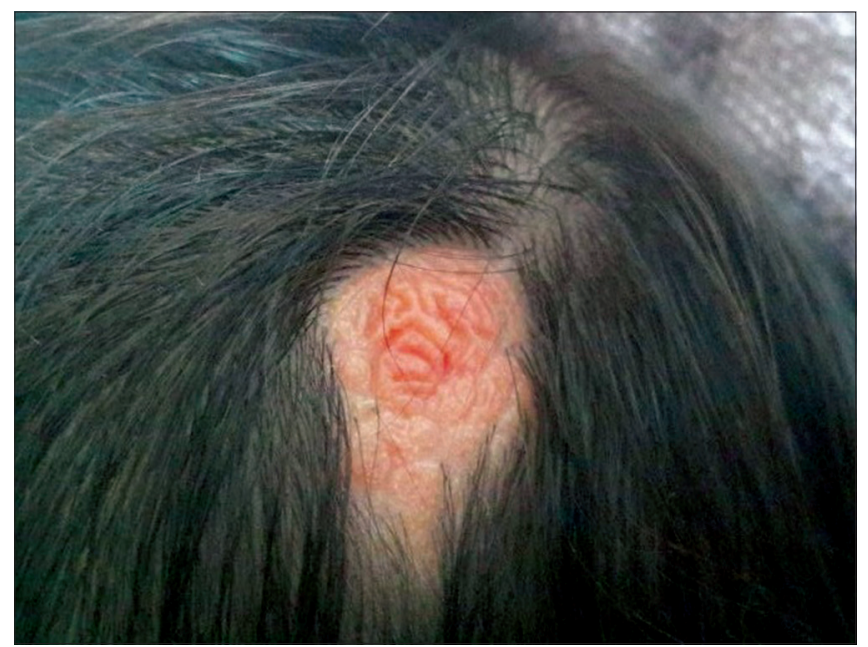

Figure 1: Cerebriform nevus sebaceous. A firm, well defined, pinkorange coloured, oval, alopecic plaque with cerebriform surface measuring $3 \times 2 \mathrm{~cm}$ on the scalp.

\footnotetext{
How to cite this article: Tamer F, Yuksel ME. Cerebriform nevus sebaceous: A rare clinical variant of nevus sebaceous. Our Dermatol Online. 2017;8(3):354-355. 


\section{www.odermatol.com}

excision and close follow up are advised because of the risk of malignant transformation [3].

\section{REFERENCES}

1. Cunha Filho RR, Fezer AP, Lorencette NA. Cerebriform sebaceous nevus: A rare presentation. Dermatol. 2015;90:602.

2. Simi CM, Rajalakshmi T, Correa M. Clinicopathologic analysis of 21 cases of nevus sebaceus: A retrospective study. Indian J Dermatol Venereol Leprol. 2008;74:625-7.
3. Avhad G, Ghuge P, Jerajani H. Cerebriform nevus sebaceous of Jadassohn. Indian Pediatr. 2013;50:1072.

4. Ezhil Arasi N, Anunayi. J, Aravinda. M. Cerebriform nevus sebaceous of jadassohn - A rare case report. Sch J Med Case Rep. 2015;3:611-3.

Copyright by Funda Tamer, et al. This is an open access article distributed under the terms of the Creative Commons Attribution License, which permits unrestricted use, distribution, and reproduction in any medium, provided the original author and source are credited.

Source of Support: Nil, Conflict of Interest: None declared. 